\title{
SELF AWARENESS OF THE SUPERVISOR IN SUPERVISION
}

\author{
Martha Gizynski
}

\begin{abstract}
Teaching self awareness is an important and sensitive task in the supervision of the clinical casework student. However, lack of self awareness on the part of the supervisor may lead to a serious impaction of this learning process, and unfortunately, there is no institutionalized process for reviewing lack of supervisory self awareness as there is for students. Some occasions in which problems in supervisory self awareness are likely to occur are: the supervisor who has difficulty in responding appropriately to the student's dependency demands in supervision, responding either by withdrawing from the student or being overprotective of him; the supervisor who is threatened by students whose character styles are very different from his own; and the supervisor who views client behavior from the perspective of a value system very different from the student's.
\end{abstract}

After an eclipse of more than a decade, clinical (nee psychiatric) casework has reemerged as a substantial area of social work education, and this development should compel a review of related dimensions in supervisory techniques and relationships. In clinical casework, the subtle nuances in the client-worker relationship are as important as technical interventions, and the supervisor is faced with the delicate and difficult task of teaching the student to be sensitive to his own impulses, responses, fantasies, and to the impact and consequences of these on the clinical relationship with his client. The supervisory task may be imperiled if the supervisor himself is unaware of the nature of his own responses, either rational or irrational, that may be provoked by the student.

The stresses and strains in the supervisory relationship have been amply documented (Rosenblatt and Meyer, 1975; Kadushin, 1974; Hawthorne, 1975; Bruck, 1963) and the dilemmas are familiar: supervisory evaluations can have a negative impact on careers long after the relationship ends; supervisors are diffident about accepting the responsibility that is commensurate with their authority; and supervision is amorphous, unsupportive, or inadequate. 
When the supervision is in clinical casework the supervisory relationship has more complicated dimensions because the student's personality, his idiosyncratic assets and liabilities, and his disciplined use and awareness of himself become a legitimate arena for supervisory scrutiny. The fantasies, anxieties, and inhibitions of a graduate student in chemistry, for instance, are the concern of no one as long as he gets his work done. The student in clinical casework enjoys no such immunity and is expected to endure the self-discipline of systematic review of his personal responses and their impact on the client-worker relationship.

Needless to say, this development of self-awareness can be exquisitely painful and threatening to even the brightest and most highly motivated student, and adds an extra burden to the supervisory relationship. The student already sees the supervisor as a powerful gatekeeper to professional acceptance, and as possessor of coveted professional expertise. Under the scrutiny of this formidable person the student must be open about disclosing his personal and sometimes irrational feelings about the client. He very much needs to feel that his supervisor accepts and respects him as a person, if he is going to be undefensive about self-disclosure. For the student, the supervisory relationship must invariably assume qualities of intimacy, vulnerability, and ambivalence, and to the degree that it does, the relationship will evoke the analogous feelings that are in the parent-child relationship. This should not be surprising; it is precisely these parameters which elicit the ghosts of the parentchild relationship or transference, in the client-worker relationship. The parallels between the concurrent client-worker and student-supervisor relationship have been charted by other clinicians (Ekstein and Wallerstein, 1958).

These circumstances leave the supervisor in the dilemma of having to be more than a teacher and less than a therapist. Inevitably this demands sensitive and difficult decisions on the part of the supervisor who must always be aware at what point his professional concern becomes personal intrusiveness, and yet deal directly and realistically with countertransference phenomena which interfere with the ongoing therapeutic work. It requires a delicate touch to couch observations so that the student is not so threatened that he becomes defensive and resistant to learning. When a student feels that he has to protect himself from painful and humiliating confrontations with the supervisor, he will withhold or monitor process material, and thereby impoverish the supervisory relationship of the complex and sensitive exchanges that should make it an arena for rich learning experiences.

I have spoken as though the self-awareness of the supervisor is taken for granted in the supervisory relationship, a comforting but unwarranted assumption. The supervisor's professional and personal concern for his student as well as his feelings about his identity both as a member 
CLINICAL SOCIAL WORK JOURNAL

of an agency and a profession make him vulnerable to the same kind of countertransference distortions in the supervisory relationship as the student has in the client-worker relationship. Lack of self-awareness in the student is a difficult but legitimate problem; lack of awareness in the supervisor invariably leads to a serious impaction of the whole learning process, and unfortunately, there is no institutionalized process for reviewing lack of supervisory self-awareness in the supervisory relationship. I would like to suggest three areas where the supervisory relationship is frequently threatened because of lack of self-awareness on the part of the supervisor; appropriateness of dependency needs, differences in personal therapeutic style, and differences in values.

\section{Dependency}

All students are realistically dependent on supervisors, for some of the reasons I have already mentioned-the supervisor's professional expertise, the power of his evaluations in the professional community, and his advocacy and guidance in the agency itself. But the clinical casework student is dependent upon (and is being evaluated upon) the supervisor's perception and understanding of the student's countertransference in the clinical relationship and his awareness and self-disciplined use of these feelings. The criteria for this task are amorphous to say the least, and since the student has so few objective clues to guide him in selfassessment he may clutch at the supervisor and inflate the omniscience and wisdom of the supervisor just as clients perceive their workers as omnipotent parents, because they need them to be. Some supervisors feel distaste or even panic when their students demand this kind of reassurance from them, and this in turn triggers some rather elaborate distancing maneuvers-maneuvers which must be understood as defensive and not be rationalized away as strategies for reinforcing the student's autonomy.

The simplest defense is to ignore the student's personal dependency expectations completely and address the supervisory task in ways which deny the existence of this dimension. The focus in supervision may be on solving social and environmental problems, in the client's life rather than intrapsychic ones. The supervisor colludes with the student's diffidence about exploring transference-countertransference issues that might be threatening, and protects himself from the intimacy that comes with student self-revelations. The externalizations of client, student, and supervisor all have the same defensive motivations. One student, who was a withdrawn and socially isolated person himself, perceived his client's depressive withdrawal and suicidal fantasies to be the consequence of his social isolation rather than the cause of it. Actually the patient was borderline and could not form close relationships because he had a deep seated terror of intimacy and the possible loss of already shaky 
ego boundaries. The student, caught up in the defensive identification with the client, worked out elaborate schemes that were calculated to increase the client's chances of meeting people and establishing object relationships, overlooking the fact that the client was not emotionally capable of tolerating any intimacy with the few objects that he had. The supervisor colluded with the externalizing strategies of the student, because he could not bring himself to identify the countertransference as such in supervision. He felt that to address the student's needs and problems with object relationships would be tantamount to inviting the student to be dependent on him, an eventuality that he sensed would be unmanageable and personally distasteful.

The problem with defensive avoidance of student dependency, whether or not it is excessive, is that interactions get set up that are very similar to those of a weary parent and a distraught three year old; the more the parent tries to pull away, the more panicky and clutching the child becomes. The solution of therapeutic problems becomes secondary to the student's pursuit of elusive supervisory reassurance. I frequently have the impression that, after "emergency" supervisory sessions, the student's relief is not so much the result of technical advice (which is usually minimal) but rather my calm presence. Whatever happens, he has touched base, he is not alone.

Perhaps the dependency demands of students are experienced as most distressing when supervisors listen as though they were professional parents rather than teachers. That is, when a child presents a problem to a parent there is an implicit demand for relief from emotional distress, to "make it all better." When a student presents a problem to a teacher, the appeal is made to the working alliance for help with analyzing a problem. The supervisor who listens as a parent will move from magical reassurance to frustration to anger, rather than analysis.

A supervisor can mismanage dependency by cultivating it instead of avoiding it. The motives for this are usually the gratifications of being perceived as an omnipotent or omniscient parent who possesses arcane professional secrets, of being admired and/or loved in general, or being seen as the student's personal advocate against an insensitive or critical agency staff. Often the student's rather straightforward anxiety about expectations about his performance and professional responsibility will be misheard by the supervisor as a request for nurturance and support. If this corresponds to a need in the supervisor to be an overprotective and infantilizing parent, he may attempt to buffer the student from all of the psychological abrasions and contusions that are inherent in the learning process; he may pick a client caseload that is not likely to present any perils or complexities; he may avoid any distressing confrontations in the supervision, or he may run interference between the student and the rest of the staff if the latter are critical of the student.

Of course, this parental benevolence has a price. The student cannot 
CLINICAL SOCIAL WORK JOURNAL

be permitted to question the omniscience of the supervisor or disagree with him since this would threaten the supervisor's omnipotent gratifications. It will also be very threatening if the supervisee demonstrates competence or the ability to function in a capable autonomous fashion. This kind of supervisor may seem to do very well with beginners in the early adolescence of their professional development, only to be very critical and resentful of the presumption of autonomy of the advanced student. Hawthorne refers to the "father knows best" ploy used by supervisors who depend heavily on status, seniority, and past experience rather than competence to validate their authority, so that real evidences of personal and professional maturity on the part of the student are seen as threatening to the parenting dimension of the supervisory relationship (Hawthorne, 1975).

The supervisor who responds as the overprotective parent is quite likely to be personally possessive of the student, particularly if advocacy is an important dimension of the student-supervisor relationship. The supervisor sends a message, overtly or covertly, that he is the one that understands the student and the student can ignore other staff members because they are unreasonably critical or in error. At worst this can result in a kind of professional folie à deux; at best, it cuts off informal access of the student to other members of the supervisory staff and tends to be a divisive factor in staff relations as a whole. Students become a narcissistic extension of the supervisor; loyalty issues tend to override expectations of clinical performance and the supervisor loses his objectivity in evaluation and freedom in teaching. As Kadushin (1968) pointed out, the supervisor is reluctant to "risk and deal with supervisee hostility and rejection ... to deny himself the sweet fruit of flattery, the joys of omniscience, the pleasures of acting therapist, the gratification of being liked."

While most supervisors would consciously abhor this kind of behavior, we all are vulnerable when we are struggling with object loss or loss of self-esteem in our private lives. An unpleasant divorce, children leaving the home for school or marriage, the death of a parent, or disappointment in the progress of a career-they are all injuries that can precipitate behavior in other areas in an attempt to compensate for the loss. The supervisory relationship can be a genuinely gratifying one for the supervisor; it is not surprising that in moments of great object need it expands to compensate for the loss of personal relationships, however destructive this development may come to be.

\section{Differences in Style}

Supervisors can be threatened by students whose personal style of interpersonal response, both in the clinical situation and outside of it, is 
very different from their own. I am referring to those characterological styles which have become an integral part of the personality, but still retain their original defensive usefulness and significance.

For instance, if a student is passive or withholding with his client for whatever reason-he is afraid of self-disclosure, afraid of revealing incompetence, afraid of active engagement of a client-this passivity may be very provocative to a supervisor whose own clinical style is more active and confronting. The converse situation can, of course, be equally abrasive; the more thoughtful, low-keyed supervisor is driven to distraction by the active student who moves into the client material, impatiently giving directions, and solving problems without listening carefully to the client's hidden agenda.

The real problem in these conflict situations is that the supervisor tends to think of his own therapeutic style, not as a personality characteristic, but as a distillation of his accumulated experience in clinical intervention. This blurred perception then makes it difficult for the supervisor to differentiate these same dimensions in the student-that is, how much of the student's response to the client is his interpersonal style and how much is due to defensive countertransference feelings. The student who is at variance with the supervisor is therefore seen not as having a different expressive or interpersonal style, but as technically naive or incompetent. The direction that the supervision then takes is not to teach technical excellence or the principles of good practice, but to reshape the student in the supervisor's image.

One can easily imagine several consequences of this vicissitude in supervision, and all of them are troubling. The student may be compliant, even talented, at being the Galatea to his supervisor's Pygmalion. The student assumes the posture, the mannerisms, the familiar phrases that constitute the form of his teacher's competence, but not the substance. Real learning is an ongoing process of the silent synthesis and integration of hard won therapeutic experiences. The cost to the student is that he surrenders genuine professional growth and maturity for a superficial approximation of his supervisor's style, even those aspects which are peripheral or irrelevant to the therapeutic task.

The student may also resist supervisory pressure, either with open conflict or by covertly withholding veridical information about the therapeutic exchanges. For example, Dr. M. became irritated by his student's detached, intellectualized interpersonal style, unaware that his student, Mr. S., defended in this way against massive anxiety about his inadequacy. Dr. M. assumed that Mr. S. was as cool and detached with his clients as he was in the supervisory hours and he sharply criticized him for the unempathic and detached way that he had responded to an agitated patient. Mr. S. heard this criticism as a personal assault, not only on his professional competence but on his personal integrity and worth as 
well. He was shaken and resentful that Dr. M. did not seem to value or respect him as a person, and he retreated even further behind the intellectualized style, which in turn provoked Dr. M. to even more ardent attack. Mr. S., terrified of making any more mistakes that might provoke criticism, became very inhibited in the client hours. He felt paralyzed, obsessing about what ploy would please Dr. M., or at least, how to avoid giving Dr. M. any further material to use against him. He began to dictate his process notes in such an abstract and discursive way that it was impossible for Dr. M. to get any feeling for the genuine affective flavor of the hours.

In any case, the student who has lost the opportunity to learn to discriminate between personal style and technique, has lost the opportunity to learn the legitimate uses of his own spontaneity and intuition therapeutically, and the rather important lesson that there is more than one way to skin a therapeutic cat. The student must learn how to couch confrontations with his client in such a way that he always shows acceptance and respect for individual differences. Certainly one of the most valued (and elusive) talents of the supervisor is his ability to point out student errors with both honesty and tact so the student feels that his integrity as a person is supported and respected, at the same time that his professional and technical skills are coming under critical scrutiny. If the supervisor is successful in achieving this delicate balance, the student will be less threatened and can spontaneously broaden and modify his stylistic approach to respond more appropriately and sensitively to varying clients.

\section{Values}

Awareness of one's values is not unrelated to awareness of one's personal style. Both are so near the core of the personality organization that one tends to assume that their rightness is self-evident. Although reflective and self-conscious review of values is a professional ego ideal, it is not always seen to be so in fact. It is in precisely in this area of value systems that students are the most challenging or abrasive. I am not suggesting that supervisors should be diffident about convictions that have been distilled from years of professional and personal experience, but rather that deeply held feelings about the rights and wrongs of human behavior must be reviewed against a background of social and cultural flux.

There is often a kind of professional generation gap in value conflicts between supervisor and student, especially in areas of drug use and sexual behavior. Supervisors tend to feel that all drug usage is maladaptive, and students, who have spent their tenderest years growing up in the drug culture of the $1960 \mathrm{~s}$, are more accepting of this and make discrimi- 
MARTHA GIZYNSKI

nations between different kinds of drugs and the frequency of usage. One of my most frequent collisions with students is around the issue of clients coming to the hours in some state of drug intoxication. I label it as a resistance, and my student sees it as just another change of mood, another dimension of the client's problems and personality, all grist for the therapeutic mill. Nevertheless, I remain adamant that I am right, because I know I am right. One of my rules (read values) is that clients are supposed to be aware, introspective, and thoughtful about their problems, and should not seize upon pleasant, oral escape routes to oblivion.

Another thorny problem is the whole area of tumultuous change in sex mores and particularly expectations around sexual behavior for women. Of course, we are all emancipated and supporters of "womens' lib," only students seem to be much more so. Since there have been real shifts in norms for sexual behavior, how does one define maladaptive behavior? Is the young woman who moves from one sexual relationship to another, acting out (as I suspect), or is she sexually liberated (as my student thinks). We may both agree that a client should carry through on her decision to abort her pregnancy, but I am probably going to anticipate that the client will suffer from guilt much more than my student feels that she will. We both agree that women should have careers if they want them, but we are probably going to feel quite differently about the consequences of leaving small children. Perhaps the social change that is most challenging and upsetting to traditional values is the current wave of voluntary childlessness. For those who feel that parenthood is an essential part of both the psychological and social aspects of being an adult, it is hard to know whether a couple's decision to remain childless represents independence and self-actualization, or whether it is narcissistic selfindulgence.

Not all value conflicts break along generational lines; conflict around authority issues are ubiquitous both for students and supervisors. Authority, both in supervisory and therapeutic relationships is based on the power that is attributed to the possessor of a valued and sought after expertise. Since the supervisor is the student's most important access to the professional collectivity both in terms of training and evaluation, his power is undeniable, real, and difficult to deny.

The central conflict is between this aspect of power and authority and the egalitarian values of social work. These ideals are inevitably modified by the reality of the teaching relationship. The super-subordinate positions hopefully reflect real differences in experience, knowledge, and competence, but also the responsibility that is commensurate with authority. This kind of authority cannot be set aside because the owner is diffident about its assumption. It is implicit in the relationship and is sustained by the need and vulnerability of the student and the client.

Nevertheless, many supervisors are uncomfortable with this power 
gradient and devise social and interpersonal fictions that attempt to deny it. For instance they may relabel supervision "consultation" and pride themselves on creating a collegial rather than a pedagogical ambience in the supervisory hour. I have had experience in agencies where this collegiality was institutionalized by the custom of addressing both the junior and senior staff by their first names. Of course this fictive equality, while relieving some supervisor anxiety, in no way changes the nagging reality that some staff are more equal than others, and places the burden of finding out who they are and how much, squarely on the discretion of the student.

Kadushin's study found that supervisees granted the supervisors the power (and authority) of their position more readily than supervisors were prepared to accept it. Students were disturbed by the ambivalence generated by the supervisory situation, which in large part reflected the ambivalence of the supervisor about his student's professional autonomy vs. his dependence in the learning situation.

The development of self-awareness is not confined to the professional training of students, or the process of the client-worker relationship. It is an inherent part of the professional growth of clinical social workers and is a process that never ends. A supervisor who can freely share with his students his own attempts to expand clinical self-awareness, models rather than merely instructs, his student in this essential skill.

\section{REFERENCES}

Bruck, M. The relationship between student anxiety, self-awareness, and self concept and student competence in casework. Social Casework, 1963, 24(3), 125-131.

Ekstein, R. \& Wallerstein, R. S. The teaching and learning of psychotherapy. New York: Basic Books, 1958.

Hawthorne, L. Games supervisors play. Social Work, 1975, 20(3), 179-183.

Kadushin, A. Supervisor-supervisee: a survey. Social Work, 1974, 19(3), 23-32.

Kadushin, A. Games people play in supervision. Social Work, 1968, 13 (July).

Rosenblatt, A. \& Mayer, J. E. Objectionable supervisory styles: student's views. Social Work, 1975, 20(3), 184-189. 